\title{
Los casos de conciencia en la novela pastoril del Siglo de Oro: casuismo y probabilismo en la Arcadia (1598) de Lope de Vega
}

\author{
Cases of Conscience in the Spanish Pastoral Novel \\ of the Golden Age: Casuistry and Probabilism \\ in Lope de Vega's Arcadia (1598)
}

\author{
Antonio Sánchez Jiménez \\ Université de Neuchâtel
}

\section{RESUMEN}

La Arcadia (1598) de Lope de Vega fue uno de los libros más exitosos de la ya monstruosa carrera del Fénix, pero pese a ello la crítica actual insiste en criticar la obra tachándola de desorganizada y superficial. Para explicar el desfase entre estas críticas y el contrastable éxito de la Arcadia en su tiempo, este trabajo analiza uno de los aspectos más censurados por los estudiosos: la construcción de los personajes del libro, concretamente la de los dos protagonistas, los pastores Anfriso y Belisarda, y la de algunos personajes secundarios. En particular, proponemos que el lector áureo debió de apreciar los personajes de la Arcadia porque estaban diseñados de acuerdo con un hábito mental típico de la época, pero totalmente ajeno a nuestro modo de pensar, el casuismo y probabilismo de la teología moral. En este contexto examinamos en detalle los «casos» de la novela, explicando cómo debió de leerlos y disfrutarlos el público áureo. Además, esta línea de investigación permite explorar la naturaleza del interés del Fénix por la casuística, y las relaciones de este modo de pensar con su oficio de dramaturgo.

Palabras Clave: Lope de Vega, Arcadia, casuística.

\begin{abstract}
La Arcadia (1598) de Lope de Vega's Arcadia (1598) was one of the most successful books in Lope's already exceptional career, but, in spite of that success, modern critics insist in their criticism of the work, which they see as disorganized and superficial. In order to explain this contrast between these complaints and Arcadia's success in Early-Modern times, we analyze one of the aspects of the work that critics reject the most: characterization, in particular of the two protagonists, the shepherds Anfriso and Belisarda, as well as some secondary characters. We claim that Golden Age readers must have appreciated the Arcadia's characters partly because Lope designed them following a way of thinking typical of the time but profoundly strange to ours: moral theology's casuistry and probabilism. In this context we examine the novel's «cases» in detail, explaining how they must have been read and enjoyed at the time. In addition, this contextualization allows us to explore the reasons behind Lope's interest for casuistry, and to relate this way of thinking to his experience as a playwright.
\end{abstract}

Key words: Lope de Vega, Arcadia, casuistry. 
La carrera literaria de Lope de Vega fue excepcional ya desde sus comienzos a finales del reinado de Felipe II, como podemos observar fijándonos en el primer libro que el Fénix dio a imprenta, la Arcadia (1598). Esta novela pastoril narra en clave los amores del duque de Alba y los del propio autor y aseguró que la ya triunfal carrera dramática del Fénix pudiera dar el salto a los libros impresos. Al menos el público de la época respondió de modo entusiasta ante el libro, del que hemos documentado diecisiete ediciones entre 1598 y 1645, más otras catorce de las que nos han llegado noticias pero que no existen en la actualidad (McGrady, 1997: 384; Morby, 1969: 140-144; Romero Barranco, 2007: 153). Tal fue la difusión de la Arcadia que de los libros áureos de entretenimiento sólo el Amadís, la Celestina y La Diana la superaron en número de ediciones y, consiguientemente, en popularidad. Como el propio Lope, su Arcadia fue un auténtico fenómeno en el ya brillante panorama de la literatura del Siglo de Oro.

$\mathrm{Su}$ éxito entre los lectores áureos contrasta claramente con la tibia recepción de la novela entre el público y crítica actuales. En parte, la falta de aprecio por la obra debe enmarcarse en el contexto de la recepción moderna de la literatura pastoril, que no goza precisamente del fervor de los lectores ${ }^{1}$. Sin embargo, el rechazo de la Arcadia va más allá del desagrado que suelen inspirar los libros de pastores, pues la crítica ha señalado en el primer texto impreso de Lope una serie de defectos que no suelen achacar a otras obras pastoriles, como La Diana (c. 1559) de Jorge de Montemayor (1996) o La Galatea (1585) de Miguel de Cervantes (1987), o incluso a otros libros menos difundidos, como la Diana enamorada (1563) de Gaspar Gil Polo (1987) o El pastor de Fílida (1582), de Luis Gálvez de Montalvo. La crítica del siglo XIX y comienzos del XX censuró la totalidad de la narrativa pastoril por artificiosa y por el «dilettantismo estético» que percibió, por ejemplo, Marcelino Menéndez Pelayo (1962: 185), pero además destacó en la contribución de Lope al género nuevos defectos: una pedantesca e impertinente erudición (Avalle-Arce, 1959: 138; 1998: 35; Crawford, 1915: 14; Goyri de Menéndez Pidal, 1950: 366; Morby, 1966: 7; 1975: 17 y 21; Ticknor, 1965: 118-119) у una estructura deficiente (Avalle-Arce, 1959: 132; Brito Díaz, 1998: 56; Morby, 1975: 19) $)^{2}$, que se hace especialmente evidente en la construcción de

\footnotetext{
${ }^{1}$ Recientemente, Luis Beltrán Almería (2010) ha expuesto magistralmente la historia de la crítica de los libros de pastores. Se dividiría en dos etapas, una caracterizada por la aceptación de las críticas de Marcelino Menéndez Pelayo, que exponemos abajo, y una segunda inaugurada por los libros de Juan Bautista Avalle-Arce (1959) y, luego, Rafael Osuna (1972) y Francisco López Estrada (1974), y que se caracterizaría por reaccionar contra el juicio negativo del santanderino (Beltrán Almería, 2010: 332). Para completar el panorama trazado por Beltrán Almería cabe señalar que ya trabajos anteriores de López Estrada (1948; 1958) y Bruce Wardropper (1957) indican un nuevo acercamiento a lo pastoril.

${ }^{2}$ La única excepción a esta corriente crítica es la de Jole Scudieri Ruggieri, que alabó la «estructura sólida» de la Arcadia en comparación con otras obras del género (1963: 579-580).
} 
los personajes y de su modo de relacionarse. Así, el protagonista, Anfriso, sería un héroe «acartonado» que sólo alcanza cierta humanidad en sus extremos de loco (Avalle-Arce, 1959: 133), y los personajes en general decepcionarían por no sufrir «ningún cambio significativo en su evolución psicológica» (Souviron López, 1997: 144). En suma, una erudición innecesaria y, sobre todo, problemas relacionados de estructura y construcción de personajes, harían de la Arcadia un «intento frustrado» (Vossler, 1940: 170), una deforme «pastoril-monstruo» (Avalle-Arce, 1959: 139) . $^{3}$.

Nuestro trabajo trata de explicar el desfase entre estas duras críticas y el contrastable éxito de la Arcadia en su tiempo, centrándose para entenderlo en uno de los aspectos censurados por los estudiosos: la construcción de los personajes del libro, concretamente la de los dos protagonistas, los pastores Anfriso y Belisarda, y la de algunos personajes secundarios, como la ninfa Crisalda y el mago Dardanio. En particular, proponemos que el lector áureo debió de apreciar los personajes de la Arcadia, cuya construcción comprendía mejor que la crítica actual porque Anfriso y compañía estaban diseñados de acuerdo con un hábito mental típico de la época, pero totalmente ajeno a nuestro modo de pensar, el casuismo y probabilismo de la teología moral. Para leer la Arcadia en el contexto de la casuística áurea, que se ha considerado una de las grandes creaciones del Siglo de Oro (Palacios, 1987: 161), explicamos primeramente las características de esta escuela de pensamiento incidiendo en su difusión en la España de Lope. A continuación, examinamos en detalle los «casos» de Anfriso y Belisarda desde un punto de vista casuístico, explicando cómo debió de leerlos y disfrutarlos el público áureo. Por último, exploramos la naturaleza del interés del Fénix por la casuística, y las relaciones de este modo de pensar con su oficio de dramaturgo.

Antes de entrar en materia propiamente dicha y de exponer la historia de la casuística áurea, debemos reconocer que existen otros factores que contribuyeron al éxito de la Arcadia y que están siendo cada vez mejor comprendidos por la crítica. Así, los trabajos sobre el trasfondo ideológico de la pastoril en general ${ }^{4}$ han fomentado lo que Rogelio Reyes Cano consideró una nueva etapa en la recepción de la Arcadia, más justa con el texto lopesco (1973: 31). Por ejemplo, José F. Montesinos ha puesto de relieve que el aparente idealismo de la obra del Fénix refleja el ambiente de la corte ducal de Alba, y que este trasfondo debió de resultar atractivo para el público áureo

\footnotetext{
${ }^{3}$ Más recientemente, Avalle-Arce ha emitido un juicio más matizado, pero todavía muy negativo, sobre la Arcadia y sobre el Lope novelista: «Lope no se sentía muy a gusto en el campo de la novela» (1998: 33). Para Avalle-Arce, sólo un escritor áureo merece la corona de novelista, Cervantes, y con el fin de sostener esa tesis el crítico argentino cree necesario destacar los esfuerzos del manco criticando los del Fénix, quien, acerca de la novela habría sentido según Avalle-Arce «algo rayano en la fascinación del neófito» (1959: 131).

${ }^{4}$ Sirvan como ejemplo los de López Estrada (1974: 165-205) y Elizabeth Rhodes (1992), que han relacionado el género con la espiritualidad de la época.
} 
(1967: 167-169) ${ }^{5}$, tanto como los poemas que pueblan el libro y que lo convierten en una auténtica antología lírica (Montesinos, 1967: 176). De modo semejante, José Manuel Trabado Cabado ha estudiado la Arcadia y su artificioso estilo como un estadio esencial en la evolución que llevaría a planteamientos esteticistas como el gongorino (1998: 356). Desde un planteamiento más general influido por las tesis de Norbert Elias (1979), Finello ha explicado cómo el idealismo y esteticismo de la pastoril en general y de la Arcadia en particular tenía un valor social en el siglo XVI (contribuían al control y refinamiento de los impulsos violentos en el contexto cortesano) que no entendemos en nuestros días (Finello, 2003: 217; 2008: 51-53). Por último, no debemos despreciar el papel que en el éxito del libro debieron de desempeñar la denostada erudición (las misceláneas didácticas hacían furor durante el siglo XVI) y el aspecto de roman à clef que tanto cacarea Lope en el prólogo y que, sabemos, contribuyó decisivamente al éxito de otros libros de pastores (Chevalier, 1974: 45-46; Senabre, 1987: 86-90). En suma, la Arcadia posee una serie de características que la hicieron exitosa (idealismo, lírica, erudición, sustrato nobiliario y biográfico), pero existe otro factor hasta ahora no estudiado por la crítica, y que explica la construcción de los personajes del libro: la casuística.

Curiosamente, la crítica ha hablado ya de casuística para referirse a una peculiaridad de la Arcadia y de los otros libros de pastores españoles: la costumbre de exponer el problema central de la obra mediante un abanico de posibilidades, relacionadas en el nivel abstracto del tema, pero no en el nivel concreto de la trama. Glosando esta característica, ya López Estrada habló de la «sutil casuística amorosa» de La Diana (1958: 1xiii), y esa imagen fue acogida con entusiasmo por Avalle-Arce. El erudito argentino vio «casuística» (1959: 28) en la Segunda Celestina y señaló también que Montemayor demuestra en La Diana su «deseo de recorrer, en la medida de lo posible, la gama psicológica del modelo —o más bien, de analizar el sentimiento en toda su complejidad-», lo que «hace que el caso amoroso no sea único sino múltiple, al punto que casi hay tantos casos como pastores» (1959: 67). Avalle-Arce repite la idea por doquier: los primeros libros de La Diana presentarían «los problemas del amor, la casuística», habría en la obra diferentes «casos de amor» y la muerte de los salvajes en el libro II sería «un holocausto a la casuística neoplatónica» que contrastaría con los demás «casos platónicos» que componen el libro (Avalle-Arce, 1959: 70, 74 y 75). Es decir, las palabras «casuística amorosa» y «casos de amor» (Avalle-Arce, 1959: 78) están omnipresentes en los grandes estudios sobre los libros de pastores españoles, y no es de extrañar que pasaran también a José Siles Artés, que hablando de Sannazaro señala que su Arcadia «ofrece una variada casuística amorosa» (1972: 46). Como prueba del éxito del término tenemos el hecho de que la metáfora haya llegado a otros estudiosos de la novela pastoril, probablemente procedente de

\footnotetext{
${ }^{5}$ En ello también ha incidido recientemente Dominick Finello (2001; 2003).
} 
López Estrada y Avalle-Arce: la usan Juan Montero - hablando sobre La Diana (1996: 1xvii)— y Finello —-sobre la Arcadia lopesca (2003: 214)—.

Lo que propone nuestro trabajo es hacer literal esta metáfora y utilizar la casuística —el casuismo teológico, o más concretamente los hábitos de pensamiento que fomentó en la sociedad - para comprender cómo Lope explora los sentimientos de los personajes de la Arcadia. Para ello debemos comenzar definiendo la casuística y explicando su evolución, pues el uso preciso del término no es el que prevalece en la actualidad. Estrictamente, la casuística es una rama de la teología moral especializada en el estudio y análisis de casos de conciencia. La palabra está íntimamente relacionada con su objeto de estudio, el caso, y de hecho procede del vocablo latino casus («evento imprevisto, azaroso, fatídico, sin precedentes»), que en terminología legal significa «hecho preciso, real o supuesto» (Fernández Cano, 2002: 490). Como apunta esta etimología, la casuística es una ciencia aplicada, un arte que consiste en aplicar los preceptos generales de una disciplina determinada (la teología moral especulativa) a ocasiones concretas particulares (casos), ya sean reales o supuestas. Los casuistas serían, pues, aquellos teólogos morales que estudiaban casos concretos (casos de conciencia), en oposición a aquellos que se dedicaban a la teología especulativa.

Ligada al caso práctico en oposición al principio general, la casuística se puede considerar como tendente a un tipo de pensamiento filosófico posibilista. Acogiéndose a este sentido autores como Jesús Santos del Cerro (2000: 433) relacionan la casuística con conceptos de la filosofía antigua, como la idea de probabilidad desarrollada por Aristóteles en los Tópicos, donde el Estagirita define las cosas plausibles como aquellas «que parecen bien a todos, o a la mayoría, o a los más conocidos y reputados» (Aristóteles, 1982: I, 1, 100a-100b, 90), acudiendo así al criterio de autoridad que sería tan criticado en los probabilistas del siglo XVI. Por su parte, Julio Caro Baroja (1985: 540) le encontró tanto a la casuística como al probabilismo (del que hablaremos abajo) antecedentes remotos en la doctrina de Carnéades de Cirene ${ }^{6}$, director de la Academia platónica durante su tercer periodo (el anti-dogmático). La lectura académica de la teoría platónica había llevado en tiempos de Carnéades a afirmar que todo el conocimiento humano procedía de apariencias, pues para los platónicos tanto el razonamiento como la imaginación y los sentidos eran claras fuentes de error. En concreto, según Carnéades «nada podía percibirse ciertamente, sino a lo sumo probablemente» (Santos del Cerro, 2000: 433). En esta tesitura resultaba imposible guiarse por principios generales absolutos, que nunca se podían percibir con total certeza, y por tanto se corría el riesgo de caer en el nihilismo. Ante esta amenaza, Carnéades postuló que en la vida real no es necesario regirse estrictamente por principios absolutos, pues es imposible saber nada con total seguri-

\footnotetext{
${ }^{6}$ El erudito vasco confiesa seguir en esto una idea de Constant Martha, expuesta en el famoso libro del helenista francés (1883).
} 
dad. Según Carnéades, en la vida práctica basta con seguir un modus operandi imperfecto, apropiado para un mundo imperfecto: tratar de aproximarse a la verdad acumulando razones o pruebas que demuestren algo con diversos grados de probabilidad o verosimilitud, es decir, calibrando la probabilidad de que algo sea cierto o no (Caro Baroja, 1985: 538-539). Según esta doctrina, lo probable, y no lo absoluto, regirá la conducta humana. Se trata de lo que Cicerón, discípulo y doxógrafo de Carnéades, expresó en sus Tusculanas con la frase «nos sequimur probabilia» («seguimos lo más probable») (2005: II, a, 353). Carnéades y Cicerón proponían, en suma, ubicarse entre la certidumbre absoluta y su opuesto tanteando, buscando un término medio de compromiso práctico, y afrontando así los matices proporcionados por los casos intermedios (Fernández Cano, 2002: 495). Como veremos abajo, esta filosofía sería retomada con entusiasmo en el siglo XVI y resulta esencial para comprender la Arcadia.

En la Roma de Cicerón este probabilismo (la búsqueda de una opinión probable que sostenga la validez de algo) o proto-probabilismo causó bastante revuelo cuando la visitó Carnéades en función de embajador de Atenas (Caro Baroja, 1985: 538). Algunos moralistas conservadores como Catón interpretaron que Carnéades caía en un relativismo sofista que tocaba en laxismo, es decir, en justificar cualquier acción humana siempre y cuando existiera una razón probable para hacerlo, sin que importara cuán insignificante fuera la probabilidad de que esa razón fuera cierta. No parece que Carnéades llegara estos extremos, pero los probabilistas fueron desde ese momento acusados de laxismo, en una polémica que llegaría al Siglo de Oro (Palacios, 1987: 179). En cualquier caso, sí que hubo laxistas entre los cristianos en tiempos de la persecución de Decio y contra ellos fulminó san Agustín en diversas ocasiones (Fernández Cano, 2002: 495-496).

De modo mucho más directo, el probabilismo también se ha relacionado con la filosofía nominalista (Palacios, 1987: 163), y en especial con el nominalismo moderado de Guillermo de Ockham y los franciscanos de la Universidad de París. Según Eduardo Moore Candelero (1956: 27), la exaltación de lo singular y el rechazo de la especulación metafísica típicos del nominalismo debieron de dejar su impronta sobre el casuismo, que precisamente se estaba desarrollando rápidamente en el París del siglo XV. Además de inspirarse en el nominalismo, el casuismo hispano del siglo XVI compartía mucho con Carnéades, pues asumía que el entendimiento humano no alcanzaba nunca certeza absoluta acerca de la licitud o ilicitud de la aplicación de principios y leyes morales (Santos del Cerro, 2000: 435). Es decir, ante la tendencia a la consideración metafísica (la reducción a los primeros principios), la casuística áurea enfatizaba la aplicación inmediata, a menudo dificultosa, de esos principios (Palacios, 1987: 164-165).

Los precedentes de Carnéades y el nominalismo son importantes para calibrar la base filosófica de la casuística áurea y para entender las polémicas que sobre esta disciplina tuvieron lugar en el Siglo de Oro, pero lo cierto es que la 
casuística tiene antecedentes inmediatos mucho más influyentes que Carnéades u Ockham, y éstos se hallan en las prácticas penitenciales de la época y en la pedagogía y ciencia moral de la universidad medieval. En cuanto a las primeras, conviene recordar que tanto el método de estudio de caso como las compilaciones de casos recibieron gran impulso por el desarrollo del sacramento de la confesión. Al pasar ésta de ser pública a privada entre los siglos VII y XI, y al imponerse como obligatoria en el Cuarto Concilio de Letrán, aparecieron libros penitenciales que, siguiendo el método casuístico, constituían catálogos de pecados que indicaban las circunstancias peculiares a cada caso y las penitencias que según esas circunstancias merecían. Eran las llamadas sumas o sumas de casos de conciencia, siendo la más difundida la de san Raimundo de Peñafort (Suma de penitentia et matrimoni, c. 1235) (Fernández Cano, 2002: 497). Este énfasis práctico en la penitencia tenía su paralelo metodológico en las aulas universitarias de la época. Así, durante la Edad Media existía un método de enseñanza basado en la resolución de casos prácticos que se consideraba típica de los estudios generales de París (recordemos el gusto de Ockham y los franciscanos parisienses por el estudio de caso), por lo que se la llamaba modus parisiensis (Fernández Cano, 2002: 493) De París lo tomó la Universidad de Salamanca, que durante la época áurea de la Escuela de Salamanca adoptó el estudio de caso como método didáctico (Moore Candelera, 1990: 234). Ya fuera directamente de París, donde estudió san Ignacio de Loyola, ya de las aulas salmantinas, el estudio de caso en general, y la teología moral casuística en particular, pasaron a ser característicos de la Compañía de Jesús (Palacios, 1987: 165). Durante el Siglo de Oro los jesuitas españoles enseñaban la moral práctica tanto a clérigos como a laicos, y produjeron un gran número de textos para su estudio, las compilaciones de casos llamadas collationes casus (casos comparados) (Fernández Cano, 2002: 493).

Así pues, el estudio de caso, y por tanto la casuística como metodología, tenía una firme base en la historia de la universidad medieval. Allí ocurrió también el nacimiento de la casuística propiamente dicha, es decir, no ya como método pedagógico general, sino concretamente como disciplina práctica integrada en la teología moral. En las universidades medievales una reputada autoridad en la materia solía enseñar la teología positiva y especulativa sobre el texto de santo Tomás de Aquino (la Suma teológica). Luego, este bagaje teórico sería puesto en práctica en una clase considerada como complementaria, en la que un profesor de menor rango explicaría teología moral. Sin embargo, esta última sección fue cobrando peso y llegó a conseguir cátedra propia, que en las universidades españolas del Siglo de Oro se llamó «cátedra de casos de conciencia» (Fernández Cano, 2002: 491). En la universidad, el método casuístico se caracterizaba por el uso de la deducción, es decir, por ejercitar los principios morales generales aplicándolos de modo práctico para resolver casos particulares. El formato de esta enseñanza tal y como la practicaron, sobre todo, los jesuitas, era la «conferencia sobre casos de conciencia». Esta conferencia consistía en una lección 
magistral de un experto o, más frecuentemente, en un debate en que se proponía un caso que los estudiantes debían resolver aplicando principios morales generales (Fernández Cano, 2002: 493).

Impulsada ante todo por los jesuitas, y en particular por los jesuitas hispanos, la casuística católica de la Edad Moderna trataba de orientar al individuo en el confuso mundo de las probabilidades dudosas, estudiando minuciosamente los hechos específicos que atañían a cada sujeto individual y a cada caso de conciencia (Fernández Cano, Lara Moreno, Melgarejo Jaldo y Bueno Sánchez, 2002: 520). Ante esta tesitura, la casuística era sobre todo un potente instrumento penitencial, que servía para llevar a cabo un examen de conciencia o introspección previa a la confesión que ayudara a encontrar las causas de los propios pecados (Fernández Cano, 2002: 500). Atento siempre al detalle y a lo particular, estudiaba con sutileza escolástica cada decisión moral de un individuo contextualizándola, es decir, examinando meticulosamente todas sus circunstancias de tiempo, lugar, frecuencia, etc. Lo aclara Garci López de Alvarado en un manual de confesión de la época: «cuál, cuándo, por qué, en qué lugar, en qué tiempo, con qué instrumentos, por quién o contra quién pecamos y en qué, por cuánto, la cantidad del pecado o daño que se hace, si fuere poco o mucho, notable o no notable» (1552: 3). A tal llegó esta sutileza en las sumas casuísticas hispanas que la Summa resolutiorum moralium pars prima et secunda de Antonio de Diana (1585-1663) cuenta con hasta 20.000 casos, que incluyen situaciones harto específicas e improbables (Fernández Cano, 2002: 501) ${ }^{7}$. Con estas precisiones el casuismo buscaba elementos para poder decidir si un acto era pecado y, de serlo, si era mortal o venial, con las esenciales consecuencias que se derivaban de ello, pues la muerte en pecado mortal aseguraba el pasaje al Infierno ${ }^{8}$.

Este casuismo moderno propiamente dicho, es decir, el casuismo como ciencia aplicada de la teología moral y con tintes probabilistas, nació en España en 1577 (Palacios, 2000: 435), pues se generalizó a partir de la difusión de la obra de un teólogo dominico de la ya mencionada Escuela de Salamanca, fray Bartolomé Medina. En ese año decisivo Medina publicó su Expositio in Primam Secundae Angelici Doctoris, un comentario sobre el texto de santo Tomás. Además a Medina se le atribuye haber acuñado el término «probabilismo» (Caro Baroja, 1985: 401), pues usó términos parecidos en frases con

\footnotetext{
${ }^{7}$ Otros casuistas españoles de renombre internacional fueron Antonio de Escobar (15981669), autor del Examen y práctica de confesores y penitentes, que alcanzó cincuenta y siete ediciones hasta 1646, Emmanuel Rodríguez, autor de una Suma de casos de conciencia (1604), Martín de Azpilicueta, autor del Enchiridium (1553) y famoso por haber defendido a Bartolomé de las Casas en su proceso inquisitorial, o el famoso Tomás Sánchez (15501610), autor de las De sancto matrimonii sacramento disputationes, abundantes en detalles escabrosos relacionados con el sexo (Fernández Cano, 2002: 501).

${ }^{8}$ En cierto sentido, el casuismo respondía a una necesidad social: solventar la angustia que provocaba el miedo a morir en pecado mortal, fomentado por el rigorismo medieval.
} 
ecos ciceronianos, como «qui probabiliter agit, prudenter agit» («quien actúa según lo más probable, actúa prudentemente» (Palacios, 1987: 177). Como las actitudes de Carnéades o Cicerón, la de Medina era una posición práctica ante la vida que permitía actuar incluso ante la dificultad, innata al ser humano, de percibir la verdad. Otros miembros de la escuela salmantina, como Francisco Suárez y Gabriel Vázquez, desarrollaron las ideas de Medina hasta mayores extremos, e invitaban a los confesores a exonerar a aquellos pecadores que no siguieran sus escrúpulos iniciales y llevaran a cabo un acto, siempre y cuando ese acto fuera disculpado según alguna opinión plausible mantenida por sabios, aunque fuera contraria al instinto moral ${ }^{9}$. El propio Medina llegó a su conclusión probabilista porque prestaba gran importancia al papel de la intención del sujeto que toma una decisión moral: para Medina «la bondad de la voluntad depende de la intención del fin» (Gómez Canseco, 2010b: 179), idea que puede recordar las polémicas tesis de Maquiavelo. Pero el probabilismo, por mucho que fuera criticado en el siglo XVIII como inmoral y acomodaticio, como laxismo, no era maquiavelismo, pues entre esa doctrina política y la teológica había diferencias esenciales: el probabilismo exige obrar de buena fe y seguir una opinión probable sostenida por sabios, aunque esa opinión parezca menos plausible que el propio escrúpulo inicial y aunque vaya en contra de éste y de la opinión general. Es decir, más que sostener de manera rigurosa que una acción era pecado mortal o no, el probabilismo examinaba y clasificaba todas las circunstancias de la decisión, haciendo de ella un «caso» concreto. Y, puesto que dadas las complicaciones de todos los casos siempre existían diversas posibilidades de actuación, el probabilismo se inclinaba por respetar el libre albedrío del pecador (Palacios, 1987: 180) y por justificar muchas decisiones morales - y no sólo una, como harían los rigoristas - con tal de que fueran probables, de que se tomaran con buena intención y de que algún doctor las hubiera justificado. Y para los probabilistas la aplicación de un principio moral a un caso determinado era probable si a) era aprobada o susceptible de ser aprobada por autores de prestigio, o b) si existían importantes razones internas que apoyaran esa aplicación (Santos del Cerro, 2000: 436 ${ }^{10}$. Tras haberla aprobado según estos criterios se quitaba un gran peso de la conciencia del pecador, como explica Luis Gómez Canseco: «una vez tomada la decisión probable con la guía de la buena intención, la conciencia queda liberada y el pecado atenuado» (2010b: 179-180).

Gómez Canseco (2010b) ha demostrado cómo estas complejidades teológicas estuvieron al orden del día en la España de la segunda mitad del siglo

\footnotetext{
${ }^{9}$ Como resume Caro Baroja, «según los probabilistas típicos, en cuestiones de moral se puede seguir la opinión menos probable, con tal de que haya, por lo menos, un doctor de cierta reputación que la sostiene» (1985: 401).

${ }^{10}$ El primer argumento (el de autoridad) se suele llamar componente extrínseco y el segundo (el de razón interna), intrínseco (Santos del Cerro, 2000: 438).
} 
XVI, pues el casuismo y probabilismo se difundían gracias a los catecismos, a los manuales de confesores y, por último, al cotidiano sacramento de la confesión (Kallendorf, 2007: 6). Tuvo, pues, una «extensión inusitada», especialmente entre los miembros de órdenes religiosas como la Compañía de Jesús o de los laicos - como Lope de Vega- que se educaron con ella (Santos del Cerro, 2000: 437). Esta innovadora teología moral estuvo tan difundida que «condicionó la vida diaria de las gentes de la época» (Gómez Canseco, 2000b: 177), especialmente en España, donde se inventó el concepto y donde prosperó hasta alrededor de 1609, momento en que además de campar en la Península se convirtió en un fenómeno paneuropeo que sólo decaería a finales de siglo (Concina, 1772: 73; Caro Baroja, 1985: 401) ${ }^{11}$. Como afirma Daniele Concina con adecuado énfasis, la casuística probabilista nació España y dominó en este país hasta comienzos del siglo XVI, momento en el que «saliendo de España invadió casi todo el mundo» (Concina, 1772: 12).

Por consiguiente, no debe extrañar que esta filosofía llegara también a la literatura del momento. W. D. Shaw la ha detectado en un lugar tan remoto de la Escuela de Salamanca como Inglaterra, en los monólogos del teatro isabelino (1999). En España, según Miguel Álvarez (1982: 238) e Hilaire Kallendorf (2007) este modo de pensar inunda la comedia áurea, que estaría impregnada del vocabulario del casuismo («caso», «acaso», «intento», «ocasión», «acomodarse», etc.) y, sobre todo, del hábito de pensar en la decisión moral como una problemática que debe ser explorada mediante un minucioso análisis racional. Por su parte, Antonio Fernández Cano afirma que «piezas del teatro español como el drama de Lope de Vega, La estrella de Sevilla, contienen casos brillantes cargados de perplejidad y resueltos con sutileza» (2002: 499). Lo cierto es que en la comedia áurea la huella del casuismo aparece especialmente cuando un personaje se para a reflexionar sobre una decisión moral, hábito que Kallendorf ha relacionado con la práctica didáctica de los jesuitas —que llevaron el casuismo y probabilismo a su máxima expresión—: tras exponer un pecado determinado,

${ }^{11}$ La caída del casuismo debe entenderse en el contexto del siglo XVII, condicionado por la rivalidad hispano-francesa y por otra disputa relacionada, la que enfrentó a intelectuales de toda Europa contra los jesuitas. En estos debates el casuismo fue considerado como algo típicamente hispano y jesuita, y comenzó a caer según se ponía la estrella de la Monarquía Hispana en Europa. Uno de los hitos de esta caída - estudiada en detalle por Caro Baroja (1985: 550-593), Fernández Cano (2002: 501-507), Jesús Santos del Cerro (2000: 440-445) y otrosfueron las Cartas provinciales (1656-1657) de Pascal. Para medir su cénit debemos tener en cuenta que el probabilismo sufriría el primer gran golpe en 1665 y 1666, cuando el papa Alejandro VII condenó varias proposiciones asociadas a esa corriente (Caro Baroja, 1985: 556; Palacios, 1987: 181). Hoy la casuística ha conseguido dejar atrás el estigma que la rodeaba desde la polémica de Pascal y se está convirtiendo en un digno objeto de estudio. Así, algunos eruditos la han situado en el origen del método del estudio de caso (Bolívar Botía, 2002; Fernández Cano, Lara Moreno, Melgarejo Jaldo y Bueno Sánchez, 2002) e incluso en el del método didáctico puesto de moda a comienzos del siglo XX por la Harvard Business School, y entonces presentado como original (Fernández Cano, 2002: 491). 
los estudiantes de los colegios jesuíticos debían presentar posibles soluciones a un caso moral concreto y después circunstancias atenuantes o complicaciones del caso. Es decir, se trataba de un método dialéctico apropiado para el teatro, lo cual quizás contribuya también a explicar el amor jesuita por el teatro como práctica pedagógica (Kallendorf, 2007: 11).

La costumbre de presentar difíciles casos de conciencia con complejas circunstancias atenuantes ha sido utilizada por Gómez Canseco para explicar el teatro cervantino (2010a: 120-125; 2010b), pero opinamos que también debe extenderse para interpretar la novelística del propio Cervantes, señaladamente casos tan complejos como los que presenta «El celoso extremeño» o «La historia del cautivo». Es más, si los métodos dialécticos de la casuística llamaron la atención de los dramaturgos áureos, Lope, creador de la comedia nueva y educado de acuerdo con los métodos jesuitas (Millé y Giménez, 1928: 46 y 49; Tomillo y Pérez Pastor, 1901: 46), debió de asumir en su práctica dramática esta metodología. De las tablas, el Fénix podría haber exportado el casuismo a la Arcadia, obra en la que no en vano los críticos suelen detectar características dramáticas (Avalle-Arce, 1959: 139; Finello, 2008: 46; Mujica, 1986: 245-246; Osuna, 1972: 240). Estas justifican una relación directa de la obra con las prácticas teológicas jesuíticas, más que, por ejemplo, con la tradición de la literatura amorosa italiana, como el libro $\mathrm{V}$ del Filococo boccacciano, que también presentaba complicados y variados casos amorosos. Aunque la influencia de esta tradición amatoria, que desembocaría en la novela sentimental, no debe ser descartada, es la orientación moral típica del casuismo hispano, y su relación con la práctica dramática del momento, lo que puede explicar algunas de las peculiaridades en la construcción de los personajes de la Arcadia. Como anunciamos en la introducción, en las páginas que siguen vamos a explorar esa posibilidad centrándonos en las peculiaridades de la pareja protagonista (Anfriso y Belisarda) y tocando de pasada los casos de dos figuras periféricas, Crisalda y Dardanio.

La característica más sorprendente de los dos primeros, Anfriso y Belisarda, está relacionada con el momento de su ruptura y con los actos vengativos que la siguieron. Anfriso, como el pastor más noble y destacado de la Arcadia, parecía destinado a ser la pareja de la bella y virtuosa Belisarda. Ésta además correspondía al joven con un amor honesto, imperturbable pese a las insistentes quejas de otros nobles pastores que la pretendían, y entre los que destacan Galafrón, Leriano y Olimpio. Lo que sí que consiguen estos malintencionados pastores al comienzo del libro es separar a los amantes, intrigando para que los padres de Anfriso le obliguen a dejar la Arcadia por un tiempo. En ese momento, y en una emotiva despedida, Belisarda le promete a Anfriso fidelidad eterna, pero pese a ello poco después de despedir a Anfriso le concede al insistente Olimpio una prenda (una ominosa cinta negra), en un acto que presencia oculto el despechado Anfriso, gracias a la magia de Dardanio y pese a encontrarse a jornadas de distancia. Al regresar a la Arcadia, Anfriso castiga a Belisarda con el tormento de los celos cortejando ostentosamente a Anarda, ante lo cual Beli- 
sarda decide vengarse de manera irreparable, casándose con el feo y despreciable Salicio. La obra acaba con el desengaño de Anfriso, que visita la cueva de la maga Polinesta para darse cuenta de que sólo el estudio de las artes liberales puede liberar el alma de los vaivenes del mundo. Sin embargo, no debemos caer en la tentación de explicar las acciones de Belisarda y Anfriso como motivadas por la necesidad de ese final pedagógico, por otra parte muy censurado por la crítica (Goyri de Menéndez Pidal, 1950: 366). La parte didáctica de la Arcadia comprende solamente el libro $\mathrm{V}$, un quinto, pues, del total, que más bien se dedica abrumadoramente a narrar los amores de Anfriso y Belisarda, trama en la que destacan las extrañas acciones arriba explicadas. Ante el desliz de Belisarda y la venganza de Anfriso, primero, y Belisarda, después, el lector de la época reaccionaría, como el de hoy, enjuiciando a los personajes y calificando sus acciones de buenas o malas. Es decir, el lector se aproximaría a los casos aplicando principios morales generales que considerara apropiados.

Imbuido de casuística, el público del Siglo de Oro realizaría esta lectura aplicando, ya fuera automática, ya conscientemente, la metodología del casuismo, es decir, analizando las circunstancias particulares de cada acción, evaluando las intenciones de los personajes y buscando el principio moral de aplicación más probable. Es más, los lectores áureos también analizarían el modo en que Anfriso y Belisarda aplican una práctica casuista para interpretar las acciones del amado o amada, y calificarían al pastor y pastora de buenos o malos probabilistas.

El vocabulario de la Arcadia invita ya a este tipo de juicios, porque incluye abundantes ejemplos de términos propios de la casuística, como «caso», «acaso», o «intento», que un lector áureo habría reconocido inmediatamente como pertenecientes a un campo semántico y jerga peculiar, especializada. Por ejemplo, cuando la sabia Polinesta intenta consolar a Anfriso, que ha llegado a su cueva en busca de ayuda para poder olvidar a Belisarda, la maga recurre a un vocabulario técnico:

- No te desconsueles de esa suerte — dijo Polinesta a Anfriso, viendo que ya se le enternecían los ojos-, que al deseo de remedio en los casos amorosos no son las medicinas imposibles. Querer un hombre olvidar y no hacer diligencias para ello, no es dar materia en que pueda imprimirse forma, sino impedir todos los caminos de la humana física. Aquí es menester que te desnudes de cuanto hasta agora ha vestido tu cuerpo: de lo que te has de vestir no ha de haberte jamás servido. (Vega Carpio, 2012: 556).

Junto a difundidos tecnicismos de índole aristotélica (referencias al hilemorfismo y a la división de sexos según esa teoría), e incluso a vocablos del campo semántico de la medicina («medicinas», «física»), Polinesta emplea también la palabra clave «casos», usada precisamente para indicar que en unas circunstancias concretas (los «casos amorosos»), las dolencias pueden ser curadas. La palabra, que podría pasar desapercibida a un lector actual, era un tecnicismo muy cargado en su momento. 
Al lado de ejemplos de índole general como el que acabamos de citar, y que abundan en la obra, tenemos las apariciones de palabras clave del casuismo en momentos decisivos de la novela. Así, por ejemplo, cuando Belisarda decide, al parecer inesperadamente, casarse con Salicio, el narrador interviene, interrumpiendo para ello la trama, y encabezando su reflexión con la llamativa palabra «caso»:

Caso es de admiración el corto espacio que una mujer pone desde la determinación al efeto y del entendimiento a las obras: como lo dijo, lo hizo, como lo pensó, lo ejecutó, y era tanta la priesa que la venganza furiosa daba al amor piadoso que cuanto el uno helaba, el otro encendía. Y como el dormir sobre las cosas suele poner cuerda remisión en ellas, aun allí no hubo esta dicha, porque también faltó el sueño, que, como los que están airados, si acaso se ven el rostro en algún espejo, templan su enojo y furia, así el sueño suele ser freno de los coléricos y letrado discreto de los vengativos. ¡Oíd, selvas, oíd cosa tan nueva y espantosa; oíd árboles, ríos, fuentes y montes, los que os coronáis de nieve y los que jamás la vistes sobre vuestras pardas peñas: Belisarda se casa por celos, sin otra consideración que su venganza; ya determina tomarla de sí misma, perdiendo a Anfriso y entregándose a Salicio por toda la vida con lazo indisoluble hasta la muerte! iA Salicio, aquel pastor que al principio os dije, feo, ignorante y presuntuoso! ¡Triste de ti, mujer precipitada y furiosa!, que al fin Anfriso, aunque queda mal, queda solo y capaz de remedio, pero tú para siempre cautiva y, por vengarte del mayor amigo, en poder del mayor enemigo. ¡Ah celos, celos! Si yo os conozco, ¿qué os culpo?, y, si no tenéis razón, ¿por qué no digo que Belisarda la tiene? Selvas, árboles, fuentes, ríos y montes, Belisarda está disculpada, oíd el suceso. (Vega Carpio, 2012: 551-552).

La crítica ha notado ya la persistencia de estos «intercolunios» (Rabell, 1992) exclamativos introducidos por el narrador en la narrativa áurea, pero no los ha relacionado todavía con la práctica reflexiva fomentada por la casuística, algo que parece evidente en el ejemplo citado. El narrador comienza definiendo lo que el lector tiene ante sí como un «caso», y estudiando minuciosamente las circunstancias que llevaron a Belisarda a actuar como lo hizo. En primer lugar, explica, la pastora actuó de modo rápido e irreflexivo, lo que constituye una primera circunstancia atenuante: «como lo dijo, lo hizo, como lo pensó». Además, la bella era pasto de pasiones tan poderosas como «la venganza furiosa» y el «amor piadoso», que obviamente la dominaban en ese momento («cuanto el uno helaba, el otro encendía»). Es más, aunque lo narrado (la decisión de Belisarda) ocurrió de noche, la pastora no había dormido, lo que también afectó a su decisión de modo negativo. A continuación, el narrador invoca a los elementos de la naturaleza para que actúen como una especie de jurado y evalúen la posible intención de Belisarda. Para ello deben tener en cuenta el hecho de que la joven se venga de Anfriso dañándose en primer lugar a sí misma, pues Salicio no es un galán atractivo, sino «aquel pastor que al principio os dije, feo, ignorante y presuntuoso». El veredicto, es decir, la aplicación del principio moral probable al caso estudiado, está ya cerca, pues estudiando las circunstancias en las que queda Belisarda («tú para siempre cautiva $\mathrm{y}$, por vengarte del mayor amigo, en poder del mayor enemigo»), el narrador concluye que la pastora ha actuado por celos, y que esta pasión explica perfectamen- 
te el comportamiento de Belisarda. En efecto, si la decisión de la bella parece irracional, ello se debe a que Belisarda actúa dominada por una fuerza irracional, como resalta el narrador: «iAh celos, celos! Si yo os conozco, ¿qué os culpo?, y, si no tenéis razón, ¿por qué no digo que Belisarda la tiene?». En este momento, la voz narrativa vuelve a apelar al jurado («Selvas, árboles, fuentes, ríos y montes») para cerrar la reflexión y llega por fin a su conclusión moral: «Belisarda está disculpada». El estudio de las circunstancias peculiares de este caso le ha permitido resolverlo, aplicando un principio moral probable: Belisarda ha actuado de modo tan extraño, perjudicándose a sí misma y eligiendo súbitamente un marido totalmente inesperado, porque se hallaba influida (y «disculpada» en su error) por una pasión exculpatoria, los celos.

Más adelante, los propios personajes llegan a conclusiones semejantes, y lo hacen de nuevo usando una palabra clave en la ciencia casuística, «ocasión»:

- Aquella noche lo determiné, después de infinitas lágrimas, sospiros y desesperaciones con que me despedí de tus crueldades. Si, engañado de tus celos, has creído que te olvidé, yo sola soy la desdichada que te perdí y cobré el tirano que tengo. Que tú sabes si en esto deseé más vengarte a ti que mi remedio y gusto.

— ¿Es posible — dijo Anfriso-, Belisarda mía, que no amabas a Olimpio y que por desesperación de verme con Anarda te has casado con Salicio?

— ¿Es posible, ingrato — respondió Belisarda-, que, creyendo que favorecía a Olimpio, fingiste amar a Anarda y diste ocasión a mi venganza para que aceleradamente me casase con Salicio? (Vega Carpio, 2012: 576).

En esta escena los antiguos amantes están explicándose lo ocurrido y detallando la circunstancias precisas que les movieron a actuar como lo hicieron, es decir, a darles «ocasión» para hacerlo. Lo que hace Belisarda es repetir para Anfriso el análisis de caso que anteriormente hizo el narrador: expone que tomó la decisión de forma precipitada y después de un día lleno de despechos («aquella noche»), y que no fue un acto malintencionado, sino irracional, como demuestra el hecho de que la propia bella fuera la mayor perjudicada en ello. Ante la evidencia de estas circunstancias, Anfriso se da cuenta (demasiado tarde) de cuál es la interpretación probable de ese caso y del anterior (la entrega de la cinta a Olimpio): Belisarda queda disculpada, pues se casó por celos y pues dio una prenda a otro sin amarle. En ese momento, Belisarda reitera las circunstancias atenuantes de su decisión (la «ocasión») y comprende también, por analogía de su caso con el de Anfriso, las motivaciones (la intención o «intento» que buscaban los casuistas) del pastor. Todo ha ocurrido de acuerdo con las costumbres difundidas por la casuística: se examinan de modo exhaustivo las circunstancias de cada acción o caso para hallar la explicación del mismo y para aplicar el principio moral más probable. De hecho, incluso la analogía, lo que usa Belisarda para entender a Anfriso, era un método típico de los casuistas: estos moralistas esperaban que mediante el minucioso análisis de otros casos los pecadores pudieran establecer analogías con su propia realidad, y examinar así la propia conciencia. 
Hemos explicado cómo la casuística se puede utilizar para comprender uno de los puntos clave de la Arcadia, el súbito y extraño matrimonio de Belisarda. Además, este hábito de pensamiento también se debe tener en cuenta para interpretar otros complejos «casos» que presenta la obra. El más chocante es el desliz de Belisarda, quien tras prometer enardecidamente y entre un mar de lágrimas que le será fiel a Anfriso hasta la muerte, sucumbe simbólicamente al concederle una prenda amorosa (la mentada cinta negra) a uno de sus pretendientes, Olimpio, y todo ello horas después de la partida de Anfriso. Es una escena sumamente curiosa porque el narrador recurre en ella a una elipsis, recurso poco corriente en la Arcadia. Tras haber relatado en estilo directo y con sumo detalle la conversación entre la bella y Olimpio, el narrador no nos proporciona el momento decisivo, el diálogo concreto en el que Olimpio le expone una razón decisiva a Belisarda y la convence, y en el que Belisarda le explica por qué le concede la cinta y en qué términos:

Comenzó Belisarda desdeñosa a negar este favor a Olimpio, como aquella que aun en cosas de pequeña importancia se recelaba de ofender a Anfriso. Pero estuvo el pastor tan pertinaz y persuadiola con tan eficaces palabras y enternecidos encarecimientos que se determinó a dársela. Y, tomando la labrada cuchar, se desató la negra lazada de los corales y se la dio de su mano al contento Olimpio. (Vega Carpio, 2012: 425).

La narración de este suceso llama la atención porque priva a los lectores de las circunstancias necesarias para interpretar correctamente el «intento» de Belisarda, y poder así resolver el caso. Esta ceguera parcial se hace eco, precisamente, de la situación en que se encuentra Anfriso, a quien el sabio Dardanio ha colocado en un lugar desde el que puede observar la escena, pero desde el que no puede oír lo que dicen Belisarda y Olimpio. Es decir, Anfriso se encuentra incluso más ayuno de circunstancias particulares que los lectores, que por lo menos han podido leer el diálogo anterior a la concesión de la cinta y saben, por tanto, que Belisarda está entristecida por la marcha de Anfriso, debilitada por el llanto y por la falta de sueño, y deseosa de librarse de Olimpio. Privado de esta información esencial, Anfriso es incapaz de aplicar un principio moral probable para juzgar el caso de la cinta negra, y fulmina una condena a Belisarda:

Estas cosas miraba desde lejos el encubierto Anfriso y, como de verlos hablar tan cerca estuviese ya desesperado, cuando vio que Belisarda le favorecía con la cinta y que en cambio tomaba la otra prenda, no entendiendo la voluntad con que se daba ni lo que había costado pedirla, ciego de cólera y celos, en pie se puso diciendo:

${ }_{-}$OOh traidora Belisarda, a quien en mi vida pensé llamar tal nombre! ¡Oh enemiga desleal al hombre más firme que jamás tuvo pensamiento amoroso! ¿Esas son las palabras que en mi partida acreditabas con lágrimas? ¿Esos son los juramentos que con tan tiernas entrañas te creyeron mis engañadas confianzas? ¿Merece mi lealtad esa traición, mi fe esa crueldad, mi amor esa ingratitud y mi firmeza esa mudanza? ¿En tan poca y breve ausencia diste, cruel, las tuyas a ajenas manos y adornan en tan breve ausencia prendas tuyas? Primero el cielo me con- 
suma con iguales rayos que a los atrevidos hijos de la tierra que se alabe ese pastor que ha gozado a mis ojos favor que en otros tiempos costara tantas lágrimas a los míos, que yo volveré rojas las verdes hierbas de este prado con su traidora sangre». (Vega Carpio, 2012: 425-426).

La precipitación y, sobre todo, la insistencia de Anfriso en condenar a Belisarda sin haberla siquiera oído, y sin conocer del todo las circunstancias del caso, será lo que provoque la ruina de los amantes. De hecho, podemos interpretar este episodio como una advertencia de Lope contra las interpretaciones de los rigoristas — léase, de los amantes rigurosos-, que se apresuran a fulminar contra los pecadores — léase, contra los amantes errados - pese a que la imperfección esencial al conocimiento humano les impiden, como a todos los otros hombres, conocer la verdad de forma absoluta. Esta interpretación estaría apoyada por el hecho de que los amigos de Anfriso le explican en varias ocasiones al galán que está siendo demasiado severo con Belisarda, pero el pastor protagonista rechaza estas intercesiones y se niega a oír las circunstancias del caso de boca de la bella. Se trataría de un mensaje muy afín al que aparece de modo explícito a lo largo de la obra: el amor y sus inevitables acólitos, los celos, ciegan el entendimiento, por lo que es mejor evitar esa pasión y desengañarse mediante el estudio de cosas permanentes como las artes liberales. En este ambiente de tardío desengaño y de inevitable ceguera pasional, el rigorismo sería una actitud cruel $\mathrm{y}$, en todo caso, sumamente desaconsejable, pues la ceguera también puede afectar al que emite el juicio y aplica los principios morales. En el amor no se puede ser rigorista, sostendría Lope.

Sea como fuere, el lector también debe considerar la decisión de Anfriso como otro caso de conciencia, y juzgarla tan sólo después de haber considerado todas las circunstancias atenuantes, y la primera de ellas es precisamente el hecho de que Anfriso actúa sin conocer del todo el caso de conciencia de Belisarda, pues sólo percibe lo que le muestran sus ojos. En este sentido, Anfriso es una víctima de Dardanio, figura ambivalente donde las haya —el mago invoca a Plutón con las resonantes palabras «Príncipe de las Tinieblas» en su conjuro (Vega Carpio, 2012: 412), lo que le aproxima a la nigromancia (Blasco, 1990)_, pues el sabio ha elegido poner a Anfriso en una situación casi imposible. Llevado por Dardanio, Anfriso ha visto con sus propios ojos, primero, lo que le parecía demasiada alegría y desenvoltura por parte de Belisarda:

Llegado, pues, a un valle donde ella entonces acostumbraba llevar sus blancos ánades, viola venir hermosa y desenvuelta, no de otra suerte que por los mismos montes la cazadora Diana solía mostrarse. Y pareciéndole que venía más gallarda de lo que en ausencia suya fuera justo, comenzó a engendrar sospechas con que después todas las cosas le parecían mayores. (Vega Carpio, 2012: 419).

Obsérvese cómo el lenguaje del pasaje está diseñado para que el lector, que ha estado observando las circunstancias del caso de Belisarda, entienda ahora las del de Anfriso, comprendiendo las pasiones que le embargan: de una 
observación pretendidamente neutral del narrador sobre la apariencia y actitud de Belisarda («hermosa y desenvuelta») se pasa a una interpretación de las mismas por parte de Anfriso. Es decir, Lope también invita al lector a estudiar la decisión de Anfriso como un caso, considerando siempre las circunstancias del mismo antes de juzgarlo, y aplicando, al hacerlo, el principio moral más probable, y no el más riguroso. Al fin y al cabo, Anfriso también se debe disculpar: ha sufrido tanto que ha considerado el suicidio, ha llorado y pasado la noche sin dormir en el bosque y, sobre todo, ha sido puesto en una situación imposible por un sabio supuestamente benevolente. Porque, como afirmará luego en diversas ocasiones, Anfriso vio lo que vio claramente y con sus propios ojos: Belisarda iba demasiado contenta y arreglada y luego le entregó una prenda a Olimpio. Puesto en esa situación y acosado por unos celos comprensibles, su incorrecta decisión está cuando menos disculpada por las circunstancias.

Ese afán de colocar a los personajes en situaciones imposibles, en las cuales no se puede nunca aplicar simplemente un principio moral ${ }^{12}$, es precisamente una de las características centrales de la Arcadia y una de las cualidades más atractivas del libro. Este método de construcción de los personajes es tan típico de la casuística que tiene que haber sido influido por ella, especialmente dada la coincidencia cronológica y de vocabulario, y dada la formación jesuítica de Lope. La construcción casuística impregna toda la obra, por lo que la Arcadia no se debe calificar de «casuística del amor» tan sólo porque presente un abanico de diferentes problemas amorosos. Mucho más importante y mucho más típico de la casuística es el hecho de proponer personajes con disyuntivas morales tan complejas y con tantas circunstancias como las que enumeraban los probabilistas. La Arcadia abunda en estos personajes, cuyas situaciones constituyen verdaderos casos de conciencia con muchas soluciones posibles. Por ejemplo, en la fábula de Alasto, Crisalda engaña al enamorado gigante, pero lo hace guiada por la buena intención de

${ }^{12}$ El humanismo de los probabilistas, reticentes a condenar a los pecadores porque sabían las dificultades inherentes a la condición humana recuerda las ideas que Martha $\mathrm{C}$. Nussbaum ha localizado en la filosofía aristotélica y en la tragedia griega. Para Nussbaum, los antiguos griegos consideraban que la perfección era ajena al ser humano, pues los hombres están por definición sometidos al azar, que con sus cambiantes circunstancias les pueden arrojar a situaciones en las que sea imposible tomar una decisión moralmente correcta (2009: 2). De hecho, para Nussbaum la tragedia clásica griega exploraba la condición humana situando a los héroes en situaciones en las que tenían que elegir entre principios morales equiparables (2009: 27-30). Estas situaciones de difícil solución moral serían semejantes a las que fomentó la casuística en el siglo XVI español, y a las que Lope idea para explorar el amor de Anfriso y Belisarda. Estaríamos, pues, ante una posible corriente de pensamiento humanista y mediterráneo que iría desde la Grecia de Esquilo hasta la España de Lope, y que habría sido posteriormente rechazada por la interpretación rigorista de la naturaleza de la virtud humana -interna e inmune a las circunstancias-que según Nussbaum impera en la moral occidental desde Kant y su imperativo categórico (2009: 4). 
conservar su castidad ante lo que considera probable (que él la viole, como sugiere su fiero aspecto y su asociación con el tradicional salvaje), pese a que esa opinión resulta ser, dados los hechos que presencia la pastora, bastante menos probable que otras. No se trata, ciertamente, de opiniones de teólogos, pero ante un lector acostumbrado al modo de pensar de la casuística estas opiniones se estudiarían siguiendo un método determinado, como las que examinaba un confesor al decidir la gravedad de un pecado. Otro ejemplo es el ya citado del sabio Dardanio, cuyo caso de conciencia es acceder o no al deseo de Anfriso de ver a Belisarda, cuando el mago probablemente sabía lo que iba a resultar si concedía lo que pedía el pastor: ¿es su acción moral o inmoral? ¿Se comportó mal Dardanio al dejarle ver al joven el encuentro de Belisarda y Olimpio aun siendo consciente de que Anfriso no podía oírles y, por tanto, no disponía de la información suficiente para juzgar lo que veía? ¿O debemos interpretar que usó de un medio cruel - exponer fuera de contexto un pequeño desliz de Belisarda - para alcanzar una buena intención — desengañar a Anfriso y hacerle seguir el camino de la virtud-? Los casos se pueden multiplicar: ¿es bueno y moral el consejo de Silvio a Anfriso de darle celos a la bella Belisarda usando a Anarda?, ¿es lícito cambiar de objeto amoroso tras sufrir múltiples desengaños, como hace Olimpio, o es mejor ser constante, como Galafrón y Leriano?, etc.

Estos apasionantes casos de conciencia tienen dos consecuencias fundamentales para la Arcadia. En primer lugar, debieron de provocar la reflexión y, probablemente, la discusión de los lectores de la obra. Cuando el libro se leía a un grupo en voz alta, Lope debió de esperar de sus lectores una reacción semejante a las de los pastores que escuchan la fábula de Alasto, interrumpiéndola y opinando sobre ella, en la Arcadia: que los oyentes tomaran posiciones a favor de uno u otro personaje o posibilidad y que lo discutieran con los otros miembros del grupo. En segundo lugar, los casos de conciencia son un modo de construir personajes con compleja vida interior. Es decir, y contra lo que sostiene parte de la crítica, los personajes centrales de la Arcadia están bien construidos y delineados psicológicamente y eso es gracias a sus casos de conciencia. Los casos presentan a los personajes sufriendo tremendas dudas, explorando diversas posibilidades y vías de actuación que se abren ante ellos, evolucionando gracias a esta reflexión, tomando decisiones más o menos morales y, finalmente, experimentando las consecuencias de sus actos. Esta agonía interior se presenta en la Arcadia con el vocabulario propio de la casuística («caso», «acaso», «ocasión», «intento», etc.), en monólogos como el siguiente de Anfriso, que recuerda a un monólogo teatral de un personaje atormentado o, incluso, a un examen de conciencia:

¿Será, por ventura, Belisarda semejante en esto a las demás mujeres, habiéndola hecho el cielo en todas las demás cosas diferente? ¿Podrá olvidarme? ¿Habrame ya olvidado? ¿Eran los favores que me hizo tan fuera de lo que puede perder que aventure lo que vale por olvidarme? ¿Habrale acaso parecido bien en mi ausen- 
cia alguno de aquellos que estando yo presente le parecieron tan mal? ¿De qué sería posible que hubiese hecho eleción para su gusto? ¿De la fe de Galafrón o de la gallardía de Leriano? ¿Cuál de éstos habrá sido el más dichoso y por cuál habré yo sido desdichado? ¿Cuál saldría más galán en las fiestas? ¿Cuál tendría más ventura en agradarla? ¿Si habrá favorecido a alguno con prenda suya el día que se lidian y corren toros en el aldea?

Mas ¿cómo puede ser que tan presto haya merecido alguno lo que merecieron mis nunca vistos sentimientos, mi perdición y locura, mis celos y mis lágrimas? Pues estos tales días salía yo glorioso de semejantes favores, y todos mis enemigos con envidia. Y creo que se hallarían testigos de esta verdad si se buscase el proceso de mi vida. (Vega Carpio, 2012: 361).

Los personajes que sufren y cambian como hace Anfriso no pueden ser calificados de personajes «planos» o de tipos, como hacen algunos críticos (Souviron López, 1997: 177). Más bien, son entes complejos que, si no entendemos o entendíamos, debemos interpretar en sus propios términos, como construcciones propias de su época e impregnadas de los hábitos generados por el casuismo y probabilismo.

De hecho, esta compleja construcción y consiguiente estructura de la novela es una de las grandes contribuciones de Lope al arte de los libros de pastores. Si está relacionada, como hemos afirmado, con el casuismo, también lo está con el arte dramático, que era la literatura más cercana al espíritu del probabilismo, como ya han demostrado con creces otros estudiosos (Álvarez, 1982: 238; Gómez Canseco, 2012a; 2010b; Kallendorf, 2007). Es decir, el Fénix debió de incorporar primeramente las prácticas heredadas del casuismo para construir sus personajes dramáticos y luego, al sentarse a escribir la Arcadia, debió de aplicarlas a los libros de pastores. Al hacerlo, consiguió dejar de lado el tono lento y descriptivo de las pastorales anteriores, obteniendo algo que la crítica ha descrito como una «novela dramática» (Finello, 2003: 214). En ese aspecto estamos de acuerdo con Silés Artés, para quien «En todos estos casos tenemos el libre albedrío ejerciendo sus impulsos; los personajes se han soltado de las ligaduras del género pastoril para hacerse responsables de sus actos. Esto es lo que, a nuestro entender, confiere a la Arcadia de Lope de Vega, categoría de novela moderna» (1972: 166). Es decir, la Arcadia se libera totalmente del estatismo típico de Sannazaro para presentar personajes en conflicto, que sufren tomando decisiones y que luego experimentan las consecuencias de las mismas. La narratividad, el énfasis en las decisiones, con sus causas, dificultades y consecuencias, llega en la Arcadia a su punto culminante dentro de la tradición pastoril. Lo que sostenemos en este trabajo es que esta evolución se llevó a cabo, entre otras cosas, gracias a la influencia del casuismo.

En suma, los hábitos — que no la estricta teología— del casuismo y probabilismo son sumamente útiles para entender cómo construye Lope los personajes de la Arcadia. El casuismo fue una corriente de la teología moral y un modo de pensar posibilista que, pese a tener antecedentes en la filosofía antigua y medieval, nació en la España del reinado de Felipe II y se extendió con una fuerza sin pre- 
cedentes por la sociedad española y europea impulsada por el sacramento de la confesión. El casuismo hispánico habría influido en el modo de construir personajes dramáticos en diversos países europeos como Inglaterra y su impronta se deja ver también en la comedia nueva áurea, por lo que debió de ser especialmente potente en el creador de la misma, Lope de Vega, hombre además educado con los jesuitas, entusiastas difusores del probabilismo. De las tablas, el Fénix llevó la casuística a sus obras impresas, como demuestra su primer libro publicado, la Arcadia. El análisis de esta novela pastoril demuestra que Lope empleó en ella el vocabulario típico del probabilismo y, sobre todo, que usó la casuística para concebir la peculiar estructura y problemática de los personajes del libro, a quienes el narrador arroja en situaciones imposibles que esos mismos personajes, el narrador y los lectores debían de analizar examinando todas y cada una de las circunstancias, como si de un caso de conciencia se tratase. Este afán, poco comprendido entre la crítica actual, debió de ser uno de los factores que contribuyeron al enorme éxito de la Arcadia entre los lectores áureos. Los complejos casos de conciencia de los personajes de la obra debieron de provocar el interés y las discusiones de los lectores de la obra, que, habituados a las prácticas penitenciales inspiradas por la casuística, participarían en el libro interrumpiendo su lectura como los oyentes internos de la «Fábula de Crisalda y Alasto», en la propia Arcadia. En esas interrupciones, los lectores de la Arcadia culparían o exonerarían a tal personaje en virtud de tal o cual circunstancia de su caso de conciencia, aplicando siempre los principios morales de modo probabilista, y no rigorista, como pedía el espíritu de Lope y las costumbres de la época.

\section{BIBLIOGRAFÍA CITADA}

Álvarez, Miguel (1982). El probabilismo y el teatro español del siglo XVII. Tesis doctoral inédita. New York: New York University.

Aristóteles (1982). Tratados de Lógica (Organon) I: Categorías. Tópicos. Sobre las refutaciones sofísticas. Trad. de Miguel Candel Sanmartín. Madrid: Gredos.

Avalle-Arce, Juan Bautista (1959). La novela pastoril española. Madrid: Revista de Occidente.

Avalle-Arce, Juan Bautista (1998). «Lope de Vega ante la novela», Anuario Lope de Vega. IV, pp. 33-54.

Beltrán Almería, Luis (2010). «Una aproximación a la novela pastoril hispana», en J. M. Ferri y J. C. Rovira (eds.), Parnaso de dos mundos: de literatura española e hispanoamericana en el Siglo de Oro. Madrid: Iberoamericana, pp. 331-350.

Blasco, Javier (1990). «Entre la «magia» del amor y la «magia» de la memoria. Hermetismo y literatura en La Arcadia de Lope», Edad de Oro. IX, pp. 19-37.

Bolívar Botía, Antonio (2002). «El estudio de caso como informe biográfico-narrativo», Arbor. DXLXXV, pp. 559-578.

Brito Díaz, Carlos (1998). «Oficina y museo de la letra: dicho y deposición para las artes de la escritura en La Arcadia», Anuario Lope de Vega. IV, pp. 55-64.

Caro Baroja, Julio (1985). Las formas complejas de la vida religiosa (religión, sociedad y carácter en la España de los siglos XVI y XVII). Madrid: SARPE. 
Cervantes Saavedra, Miguel de (1987). La Galatea. 1585. Ed. de Juan Bautista Avalle-Arce. Madrid: Clásicos Castellanos.

Chevalier, Maxime (1974). «La Diana de Montemayor y su público en la España del siglo XVI», en Jean-François Botrel y Serge Salaün (eds.), Creación y público en la literatura española. Madrid: Castalia, pp. 40-55.

Cicerón, Marco Tulio (2005). Disputaciones tusculanas. Trad. de Alberto Medina González. Madrid: Gredos.

Concina, Daniele (1772). Historia del probabilismo y rigorismo. Trad. de Matías Joaquín de Imaz. Vol. I. Madrid: Matías Fernández.

Crawford, J. P. Whickersham (1915). «The Seven Liberal Arts in Lope de Vega's Arcadia», Modern Language Notes. XXX, pp. 13-14.

Elias, Norbert (1979). Uber den Prozess der Zivilisation: Soziogenetische und psychogenetische Untersuchungen. 2 vols. Frankfurt: Suhrkamp.

Fernández Cano, Antonio (2002). «La casuística: un ensayo histórico-metodológico en busca de los antecedentes del estudio de caso», Arbor. DXLXXV, pp. 489-511.

Fernández Cano, Antonio, Teresa Lara Moreno, Juan de Dios Melgarejo Jaldo y Ángel Bueno Sánchez (2002). «Un debate metodológico entre dos aproximaciones al estudio de caso: caso de conciencia frente a estudio de caso histórico-humanista», Arbor. DXLXXV, pp. 513-532.

Finello, Dominick (2001). «La contemporaneidad de la novela pastoril española», en Isaías Lerner, Isabel Lozano Renieblas y Juan Carlos Mercado (eds.), Silva. Studia Philologica in Honorem Isaías Lerner. Madrid: Castalia, pp. 245-255.

Finello, Dominick (2003). «Alba de Tormes y el ambiente dramático en torno a la Arcadia», Anuario Lope de Vega. IX, pp. 211-224.

Finello, Dominick (2008). The Evolution of the Pastoral Novel in Early Modern Spain. Brepols: Arizona State University.

Gil Polo, Gaspar (1987). Diana enamorada. 1564. Ed. de Francisco López Estrada. Madrid: Castalia.

Gómez Canseco, Luis, ed. (2010a). La Gran Sultana doña Catalina de Oviedo. De Miguel de Cervantes. Madrid: Biblioteca Nueva.

Gómez Canseco, Luis (2010b). «Probabilismo en Cervantes: La gran sultana como caso de conciencia», Criticón. CIX, pp. 167-186.

Goyri de Menéndez Pidal, María (1950). «La Celia de Lope de Vega», Nueva Revista de Filología Hispánica. VI, pp. 347-390.

Kallendorf, Hilaire (2007). Conscience on Stage. The Comedia as Casuistry in Early Modern Spain. Toronto: University of Toronto Press.

López de Alvarado, Garci (1552). Breve compendio de confesión. Venecia: Giovanmaria Bonelli.

López Estrada, Francisco (1948). La Galatea de Cervantes: estudio crítico. Tenerife: Universidad de La Laguna.

López Estrada, Francisco, ed. (1958). Los siete libros de la Diana. De Jorge de Montemayor. Madrid: Espasa Calpe.

López Estrada, Francisco (1974). Los libros de pastores en la literatura española. La órbita previa. Madrid: Gredos.

Martha, Constant (1883). Études morales sur l'antiquité. París: Hachette.

McGrady, Donald (1997). «Introducción», en Donald McGrady (ed.), Lope de Vega. Prosa, I. Arcadia. El peregrino en su patria. Madrid: Biblioteca Castro, pp. ix-xxiv.

Menéndez Pelayo, Marcelino (1962). «La novela pastoril», en Marcelino Menéndez Pelayo, Orígenes de la novela. Vol. II. Madrid: Consejo Superior de Investigaciones Científicas, pp. 185-346.

Millé y Giménez, Juan (1928). Estudios de literatura española. La Plata: Humanidades.

Montemayor, Jorge de (1996). La Diana. Ed. de Juan Montero. Barcelona: Crítica.

Montero, Juan, ed. (1996). La Diana. De Jorge de Montemayor. Barcelona: Crítica. 
Montesinos, José F. (1967). Estudios sobre Lope de Vega. Salamanca: Anaya.

Moore Candelera, Eduardo (1956). La moral en el siglo XVI y primera mitad del XVII. Ensayo de síntesis histórica y estudio de algunos autores. Granada: Francisco Román Camacho.

Moore Candelera, Eduardo (1990). «Los jesuitas en la historia de la teología moral», Studia Moralia. XXVIII. 28, pp. 223-245.

Morby, Edwin S. (1966). «El Libro de suertes de la Arcadia», en Antonio Rodríguez Moñino (ed.), Homenaje a Rodríguez-Moñino: estudios de erudición que le ofrecen sus amigos o discípulos hispanistas norteamericanos. Vol. II. Madrid: Castalia, pp. 1-8.

Morby, Edwin S. (1969). «La Arcadia de Lope. Ediciones y tradición textual», Ábaco. I, pp. 135-233.

Morby, Edwin S., ed. (1975). Arcadia. De Lope de Vega Carpio. Madrid: Castalia.

Mujica, Barbara (1986). Iberian Pastoral Characters. Washington: Scripta Humanistica.

Nussbaum, Martha Craven (2009). The Fragility of Goodness: Luck and Ethics in Greek Tragedy and Philosophy. New York: Cambridge University Press.

Osuna, Rafael (1972). La Arcadia de Lope de Vega: génesis, estructura y originalidad. Madrid: Anejos del Boletín de la Real Academia Española.

Palacios, Bonifacio (1987). «Teología moral y sus aplicaciones, 1580-1700», en Melquíades Andrés Martínez (ed.), Historia de la teología española II. Desde el siglo XVI hasta la actualidad. Madrid: Fundación Universitaria Española, pp. 161-208.

Rabell, Carmen R. (1992). Lope de Vega: El arte nuevo de hacer «novellas». Londres: Tamesis.

Reyes Cano, Rogelio (1973). La Arcadia de Sannazaro en España. Sevilla: Universidad de Sevilla.

Rhodes, Elizabeth (1992). The Unrecognized Precursors of Montemayor's Diana. Columbia: University of Missouri Press.

Romero Barranco, Violeta (2007). «Más páginas olvidadas de la Arcadia de Lope de Vega: una nueva variante en la edición valenciana de 1602», Anuario Lope de Vega. XIII, pp. 153-162.

Santos del Cerro, Jesús (2000). «Una teoría sobre la creación del concepto moderno de probabilidad: aportaciones españolas», Llull. XXIII, pp. 431-450.

Scudieri Ruggieri, Jole (1963). «Notas a la Arcadia de Lope», Cuadernos Hispanoamericanos. CLXI-CLXII, pp. 577-605.

Senabre, Ricardo (1987). Literatura y público. Madrid: Paraninfo.

Shaw, W. D. (1999). «Masks of the Unconscious: Bad Faith and Casuistry in the Dramatic Monologue», English Literary History. LXVI, pp. 439-460.

Siles Artés, José (1972). El arte de la novela pastoril. Valencia: Albatros.

Souviron López, Begoña (1997). La mujer en la ficción arcádica. Madrid: Iberoamericana.

Ticknor, George (1965). History of Spanish Literature. 1849, Vol. II. Nueva York: Frederick Ungar.

Tomillo, [Anastasio] y [Cristóbal] Pérez Pastor (1901). Proceso de Lope de Vega por libelos contra unos cómicos. Madrid: Real Academia de la Historia.

Trabado Cabado, José Manuel (1998). «Poética y manierismo en La Arcadia de Lope de Vega», Anuario Lope de Vega. IV, pp. 347-357.

Vega Carpio, Lope de (2012). Arcadia. Prosas y versos. 1598. Ed. de Antonio Sánchez Jiménez. Madrid: Cátedra.

Vossler, Kart (1940). Lope de Vega y su tiempo. Trad. de Ramón Gómez de la Serna. Madrid: Revista de Occidente.

Wardropper, Bruce W. (1951). «The Diana of Montemayor: Reevaluation and Interpretation», Studies in Philology. XLVII, pp. 126-144. 